Effective versus Ineffective Schools: Observable Differences in the Classroom

Author(s): Charles Teddlie, Peggy C. Kirby, Sam Stringfield

Source: American Journal of Education, Vol. 97, No. 3, (May, 1989), pp. 221-236

Published by: The University of Chicago Press

Stable URL: http://www.jstor.org/stable/1085165

Accessed: $15 / 07 / 2008$ 22:18

Your use of the JSTOR archive indicates your acceptance of JSTOR's Terms and Conditions of Use, available at http://www.jstor.org/page/info/about/policies/terms.jsp. JSTOR's Terms and Conditions of Use provides, in part, that unless you have obtained prior permission, you may not download an entire issue of a journal or multiple copies of articles, and you may use content in the JSTOR archive only for your personal, non-commercial use.

Please contact the publisher regarding any further use of this work. Publisher contact information may be obtained at http://www.jstor.org/action/showPublisher?publisherCode=ucpress.

Each copy of any part of a JSTOR transmission must contain the same copyright notice that appears on the screen or printed page of such transmission.

JSTOR is a not-for-profit organization founded in 1995 to build trusted digital archives for scholarship. We work with the scholarly community to preserve their work and the materials they rely upon, and to build a common research platform that promotes the discovery and use of these resources. For more information about JSTOR, please contact support@jstor.org. 


\title{
Effective versus Ineffective Schools: Observable Differences in the Classroom
}

\author{
CHARLES TEDDLIE \\ Louisiana State University \\ PEGGY C. KIRBY \\ University of New Orleans
}

SAM STRINGFIELD

Northwest Regional Educational Laboratory

\begin{abstract}
Until recently, the areas of school effectiveness and teacher effectiveness were examined separately. The study described in this article investigated differences at the classroom level in effective and ineffective schools. Teachers in more effective schools scored consistently higher on all identified dimensions of effective teaching. Field notes from observations in one matched pair of schools suggested possible school-level factors contributing to these classroom differences. The authors suggest that an astute, highly visible administrator and clear academic focus facilitate effective teaching, but they recognize that there may also be a reciprocal increase in school-effectiveness variables (such as quality of leadership and academic mission) resulting from the cultivation or appointment of effective teachers.
\end{abstract}

The research areas of school effectiveness and teacher effectiveness have developed separately over the past 20 years, with few researchers studying school-level and teacher-level variables simultaneously. According to Good and Brophy (1986), researchers of school effectiveness have not studied classroom-process variables as closely as have teachereffectiveness researchers. While there is mounting evidence that instructional variables account for important variance between schools, Good and Brophy concluded "to date not a single naturalistic study of effective schools provides basic data (means and standard deviations 
for each classroom) to demonstrate that the behavior of individual teachers in one school differs from the behavior of teachers in other schools" (p. 586).

Stringfield et al. (1985) first verified that teachers in an effective school behave differently from teachers in an ineffective school. Using data from the third phase of the Louisiana School Effectiveness Study (LSES-III), these authors demonstrated that a school designated as effective had teachers who displayed almost double the mean percent of interactive teaching as that displayed by teachers at an ineffective school. Interactive teaching was measured using the classroom snapshot (CS) from the Stallings Observation System (Stallings and Kaskowitz 1974; Stallings 1980).

The results presented here build on those previously presented by Stringfield et al. (1985) for one pair of schools. Data from all eight pairs of schools in the LSES-III sample are examined. The data that serve as the primary focus of this study were derived from highinference classroom observation instruments (COI) that were administered in the classrooms in addition to the low-inference CS.

The COI was developed to allow researchers to record information on a variety of behaviors that are generally considered to constitute effective teaching. In developing this open-ended instrument, the authors reviewed several articles that summarized characteristics of effective teaching (Anderson 1982; Emmer and Evertson 1981; Hathaway 1983; Levin and Long 1981; Rosenshine 1983). In particular, the work of Rosenshine was used in developing the 14 indicators of effective teaching that were included on the COI. Rosenshine developed a list of six instructional functions that were commonly identified as necessary for effective teaching: (1) review of previous learning, (2) proper demonstration or presentation of new material, (3) guided group practice, (4) appropriate feedback and correctives, (5) guided independent practice, and (6) periodic review.

Charles Teddle is associate professor of Research and Statistics at Louisiana State University in Baton Rouge. He specializes in schooland teacher-effectiveness research. PEGGY C. KIRBY is assistant professor of Educational Leadership and Foundations at the University of New Orleans and codirector of the UNO Principals' Center. SAm STRINGFIELD is director of the field office of Northwest Regional Educational Laboratory. His research activities have included effective teacher behavior, program evaluation, and school effectiveness. 
These six functions cannot be assessed using a measure of time on task such as Stallings's CS in isolation. The COI allowed the researchers to complete qualitative field notes on how teachers addressed each of the instructional functions identified by Rosenshine. These qualitative field notes were initially seen as the basis for case studies that would verify and expand on more readily quantified data gathered in LSESIII, such as the CS and achievement test scores.

The need for more qualitatively oriented research in school effectiveness has been voiced elsewhere (Donmeyer 1985; Shoemaker and Fraser 1981). While early studies of school effectiveness (e.g., Weber 1971) emphasized the case study approach, more recent process-product studies (e.g., Brookover et al. 1979; Teddlie et al. 1984) have focused on multivariate models predicting the relationship between measures of school effectiveness and student achievement. In this study, information gathered from the COI complemented other, more quantitative data sources.

The LSES-III used the outlier approach (Purkey and Smith 1983) to categorize schools as effective or ineffective. This approach typically involves the use of a mathematical model to predict school-level student achievement based on factors such as the socioeconomic status (SES) of the students' families. If actual school-level achievement is significantly above expected achievement, the school is classified as effective. If it is below expectation, the school is considered ineffective. In LSES-III, a prerequisite for inclusion as an effective or ineffective school was consistent superior or inferior performance over a two-year period. School effectiveness is defined in this study in terms of expected versus actual student achievement over a two-year period. While others might prefer a more comprehensive definition, operationalizing the construct proves to be problematic. This research might more appropriately be considered a study of teacher or school effects rather than teacher or school effectiveness.

The question of stability of effective schooling, however, raises more important issues. If a school is consistently effective, what variables make it successful? What kinds of behaviors on the part of teachers, principals, and students lead to consistently superlative or consistently inferior performance?

This article is a report on an empirical test of one essential question: Do teachers in effective schools behave in a consistently different way from teachers in ineffective schools on identified indicators of effective teaching?

A second question logically follows. If teachers behave differently in effective, as opposed to ineffective, schools, what produces these differences in behavior? In this study, data obtained from use of the 


\section{Effective versus Ineffective Schools}

COI in eight matched pairs of schools are used to address the first question, while extensive field notes provide tentative answers to the second.

\section{Methods}

\section{Sample}

The sampling pool consisted of 13 school systems. Within systems, third-grade school means on the total reading section of the state basic skills test (BST) were obtained. Mean scores by school were computed for two consecutive years. Regression models predicting mean BST reading scores from mother's education, father's profession, and student body racial composition were developed for each large school system and for contiguous rural systems.

The final sample was to consist of nine pairs of schools-three rural pairs, three urban pairs, and three urban-to-suburban pairs-representing all geographic regions of the state. Within these constraints, schools were selected that scored above (or below) achievement prediction both years, with one year being substantially above (or below) prediction. Purkey and Smith (1983) suggested that outlier studies should consist of schools that had been demonstrated to be consistently positive or negative outliers.

The decision rule used to classify schools as outliers was that the Cook's $D$, a measure of influence on the regression model based on the Studentized residual (Cook 1979), had to be greater than 2.0 or less than -2.0 at least one year and had to be in the same direction both years. Rousseeuw and Leroy (1987) recommend that plus or minus 1.0 be considered a cutoff value because "most authors indicate that a Cook's $D$ of about 1.0 would be considered large" (p. 228). The cutoff score refers to the fact that removal of an observation with such a high Cook's $D$ would have a large influence on the regression model. In fact, the average of the absolute values of the Cook's $D$ across years for the outliers in this study was 2.667. The average positive outlier Cook's $D$ was 2.56 , while that of the negative outlier was -2.78 .

In addition to the aforementioned selection criteria, the identified school had to have a matching opposite directional outlier of similar racial composition within that system (or in a contiguous rural system). Only one system contributed two pairs of schools. The third-grade system in one school proved, on observation, anomalous within that school. While the school had been matched on SES, the third graders were not socioeconomically similar to the other students in that school 
or to the third graders in the matching school. This grade level was called the school's "integration" grade and had students from a lower SES than that found in the other grades in the school. The pair was therefore dropped after the fall observations. This left eight matched pairs in the school sample.

\section{Instrumentation}

An observation form to structure field notes was developed on the basis of the six teaching functions identified in Rosenshine's (1983) synthesis of teacher-effectiveness research. Fourteen general indicators with specific cues under each were used to guide qualitative data collection. The general topics were time on task, daily review, presentation of new content, initial student practice, independent practice, weekly and monthly review, teacher expectation, positive reinforcement, evaluation of student progress, lesson plans, number of interruptions, discipline, ambience, and physical characteristics of the room. Specific cues under "initial student practice," for example, included high frequency of questions, teacher-directed exchange, teacher prompts, opportunity for all students to respond, and success rate of 80 percent during initial learning. (For further clarification of the specific indicators of effective teaching, see Rosenshine [1983], pp. 335-51.)

Field notes from individual observers were later analyzed by independent raters. Considering all notes for any given teacher, two raters scored each of the indicators of effective teaching as being "evident," "contradictory or weak," "not evident," or "not observable." The last category, "physical characteristics of the room," was subdivided into "display of student work" and "teacher input in creating attractive environment," thus resulting in 15 ratings per observation.

All "not observable" ratings were eliminated. Other ratings were scaled from 1 (evident) to 3 (not evident) and averaged across raters by teacher and school. These converted data would be used to indicate differences in classrooms of effective versus ineffective schools. Closer inspection of observers' field notes was used to supplement conclusions regarding overall trends that emerged.

Five of the 15 characteristics were observable in less than threefourths of the 116 classes visited. Because elementary school classes are typically divided into time blocks of more than one-hour duration, deletion of these items seemed prudent. "Daily review," "weekly and monthly review," and "initial student practice" would require that the lesson be observed from its actual beginning to end and not in onehour frames. Likewise, "systematic evaluation" and "lesson plans" would 


\section{Effective versus Ineffective Schools}

require consultation with the teacher as these were, in most cases, not discerned from actual instruction. On further consideration, these five characteristics were deemed inappropriate to evaluate in multiple onehour time frames and were eliminated from further analyses. (The typical third-grade classroom was observed for a minimum of 12 hours during the study.) The conversion of field notes via the rating scale thus resulted in a numerical index of teacher effectiveness for 10 of the 15 general indicators.

\section{Procedure}

Each school in the sample was visited by a two-person team for three full school days in both the fall and spring of the school year. Observers were unaware of the classification-effective or ineffective-of the schools they visited. Each observer on the team visited every thirdgrade class for at least one class period each day. No school in the study contained over four third-grade sections. The remaining time allocated for classroom instruction was used to observe randomly chosen non-third-grade classes. One hundred and sixteen separate classes were visited.

Observers were instructed to begin taking notes one minute after the designated academic time had begun. These instructions proved ambiguous in the fall observation period; raters inconsistently started actual recording. Some observers began one minute after the official time designated for teaching started, while others waited until one minute after actual teaching had begun. Instructions were clarified for the spring observations such that all ratings began one minute after classes were scheduled to start. Although fall and spring data proved to be quite similar, it was felt that some indicators, such as time on task, would be inaccurately represented by inclusion of the fall data. Results reported here include spring data only.

Pairs of independent raters converted these field notes to quantitative ratings using the method described earlier. Percent agreement between raters on the 10 indicators of effective teaching ranged from .71 to .85 , with an average overall agreement of .80 .

\section{Results}

The results of this study indicate differences in classroom behavior for teachers in effective and ineffective schools. Data were analyzed at both the school and the classroom levels. Sirotnik and Burstein 
(1985) and Hanson et al. (1986) have recently cautioned against analyses at only one level (i.e., school or class or student). By finding consistent results at both the school and classroom levels, these results are enriched.

\section{School-Level Comparisons}

As shown in table 1, schools classified as effective displayed, on average, more evidence of effective teaching characteristics than did schools classified as negative outliers. Mean differences were statistically significant on seven of the 10 indicators and approached statistical significance on two others. This demonstrates that effective schools do indeed tend to have teachers whose behavior differs from that of teachers in less effective schools.

\section{Teacher-Level Comparisons}

When the teacher rather than the school is used as the unit of analysis, consistently superior performance is again revealed in schools classified

\section{TABLE 1}

Comparison of Means by School Type on 10 Dimensions of Effective Teaching

\begin{tabular}{|c|c|c|c|c|c|}
\hline \multirow[b]{2}{*}{ VARIABLE } & \multicolumn{2}{|c|}{$\begin{array}{l}\text { EFFECTIVE } \\
\text { SCHOOLS } \\
(n=8) \\
\end{array}$} & \multicolumn{2}{|c|}{$\begin{array}{l}\text { INEFFECTIVE } \\
\text { SCHOOLS } \\
(n=8) \\
\end{array}$} & \multirow[b]{2}{*}{$t$} \\
\hline & $M$ & SD & $M$ & SD & \\
\hline Time on task & 1.33 & .31 & 1.98 & .65 & $2.55^{*}$ \\
\hline Presentation of new material & 1.45 & .34 & 2.01 & .39 & $3.06^{* *}$ \\
\hline Independent practice & 1.65 & .69 & 2.24 & .49 & 1.97 \\
\hline High expectations & 1.25 & .18 & 1.84 & .51 & $3.15 *$ \\
\hline Positive reinforcement & 1.40 & .28 & 1.71 & .28 & $2.24 *$ \\
\hline Interruptions minimal & 1.43 & .56 & 2.06 & .56 & $2.25 *$ \\
\hline Discipline & 1.32 & .28 & 1.76 & .42 & $2.46 *$ \\
\hline Friendly ambience & 1.29 & .30 & 1.68 & .41 & $2.22 *$ \\
\hline Student work displayed & 1.54 & .29 & 1.70 & 61 & .69 \\
\hline Appearance of room & 1.35 & .33 & 1.58 & .30 & 1.47 \\
\hline
\end{tabular}

NOTE. $-1=$ evidence of effective behavior; $2=$ contradictory or weak evidence; $3=$ absence of effective behavior.

$* p<.05$.

$* * p<.01$. 


\section{Effective versus Ineffective Schools}

as more effective. Teachers in more effective schools demonstrated stronger teacher behaviors on all 10 effectiveness indicators (see table 2). These differences were statistically significant for nine of the 10 categories.

A multivariate analysis of variance (MANOVA) was used to analyze the teacher-level data to ensure that the significant findings were not merely a result of multiple comparisons. When the school type (effective or ineffective) was used as the independent variable and the $10 \mathrm{di}-$ mensions of effective teaching as the dependent variable, the multivariate effect was significant $(F[10,48]=2.5, p<.016)$, indicating an overall effect for type of school on teacher behaviors in the classroom.

\section{Comparisons of Paired Schools}

The differences in classroom behavior according to school classification were also consistent within matched pairs of schools. Teacher means and standard deviations on four of the 10 effective teaching dimensions are presented in table 3 by matched pairs of schools. The positive outlier (more effective) school in pair 8 scored slightly poorer on three of the four chosen dimensions than did its negative match. One other pair tied in the discipline category, and the negative outlier in another pair outperformed its positive counterpart in this category. However, in all other cases teachers in the schools classified as more effective demonstrated superior teaching skills. These findings cannot be attributed to one or two particularly outstanding (or inept) teachers, since very little variability was discovered in many teacher ratings in schools of either classification. For example, there was no variability in time-on-task ratings in one school and no variability in teacher expectations in another. Standard deviations were less than 1.0 in all cases and less than .50 in one-third of the cases listed in table 3.

\section{Sample Case}

The data from one pair of schools are presented here to demonstrate the consistent differences found in teacher behaviors across schools. The pair of schools was chosen for more in-depth analysis because the two schools were located close to one another and served students from the same neighborhoods. Teacher means and standard deviations on all 10 effective teaching dimensions for this matched pair are presented in table 4 . Teachers in the positive outlier school were rated as more effective on all 10 teaching dimensions. It should be noted 


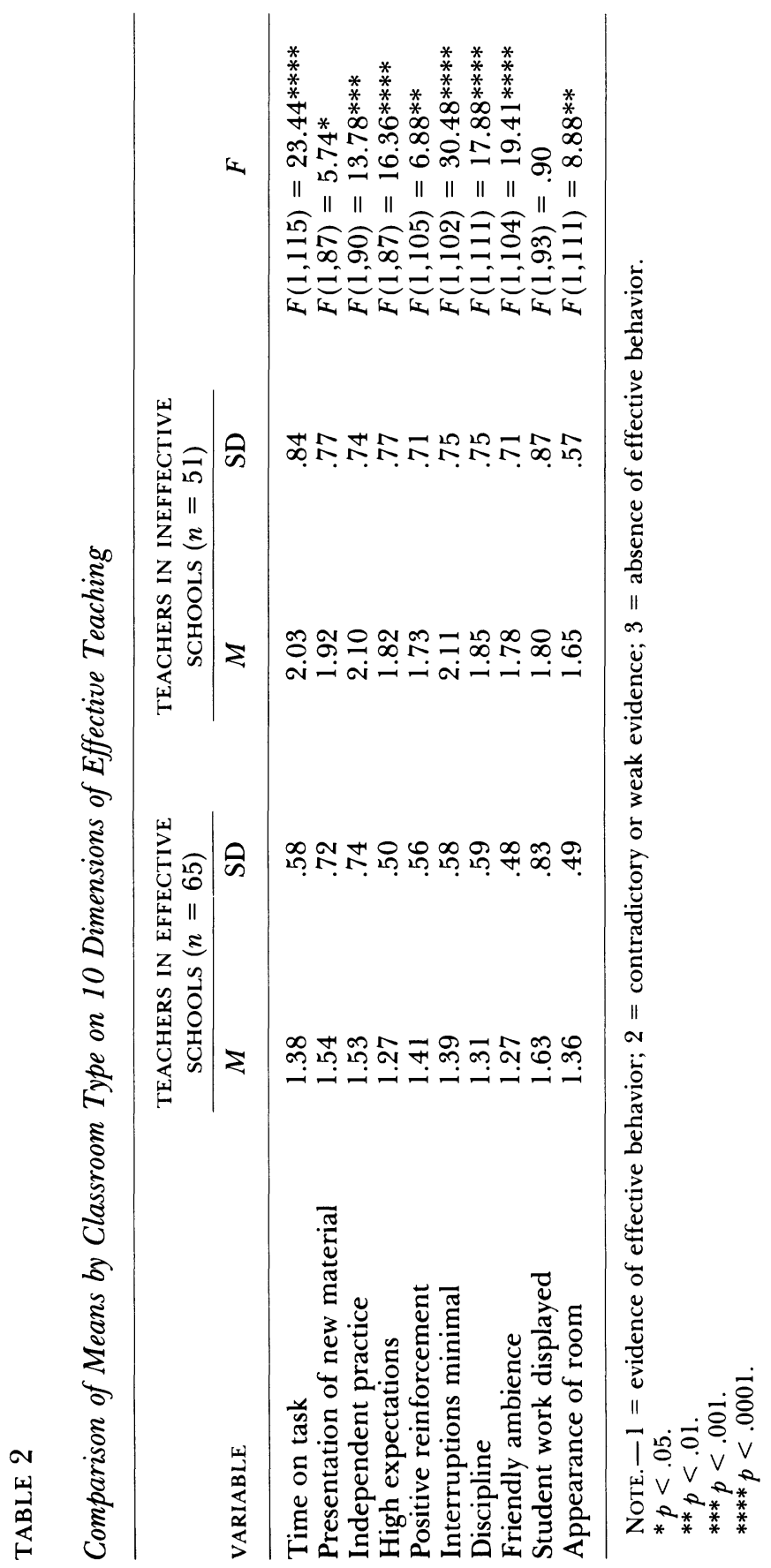




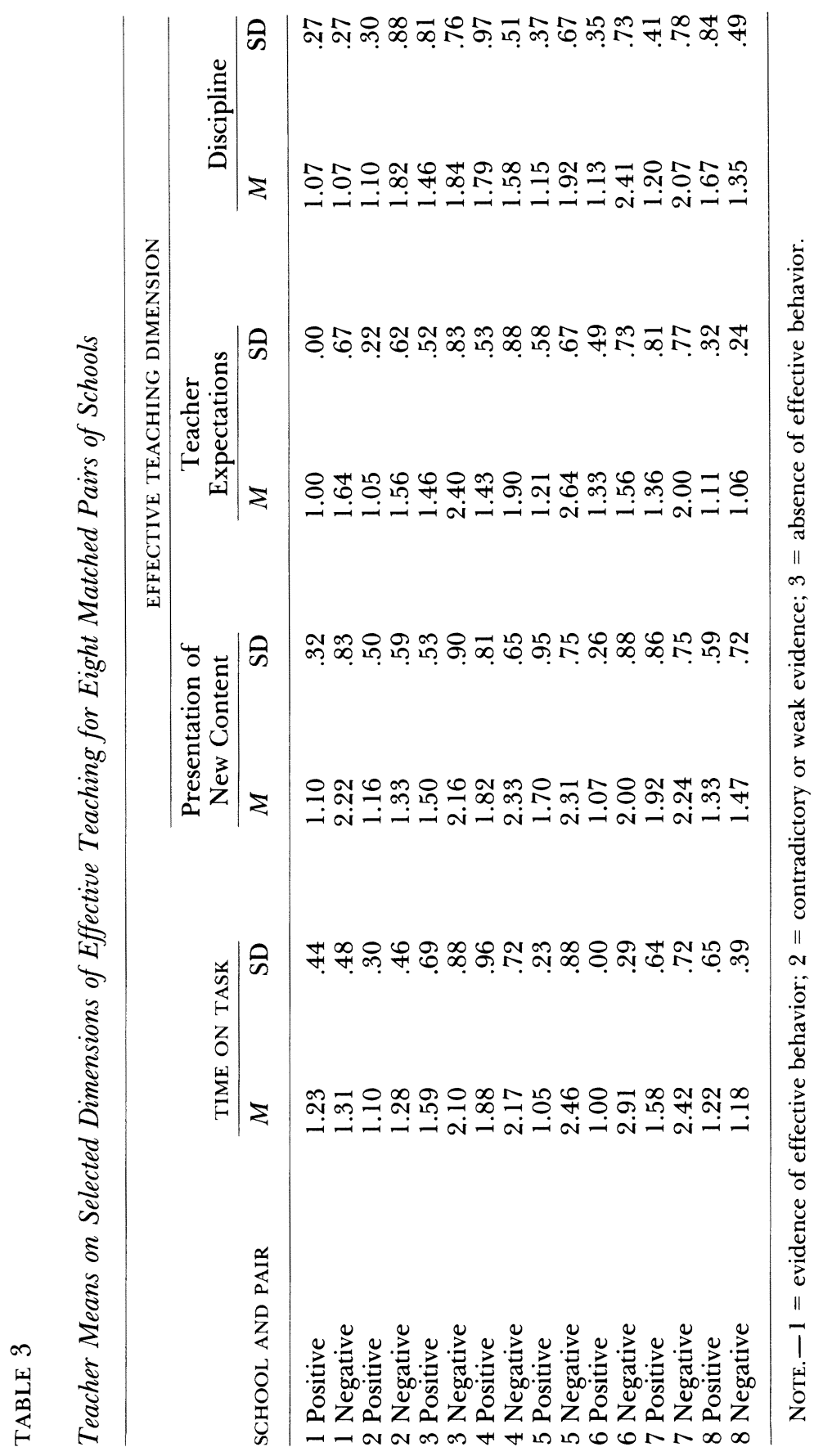


Teddlie et al.

TABLE 4

Comparison of Teacher Means by School Type for One Matched Pair of Schools

\begin{tabular}{lccccc}
\hline & \multicolumn{2}{c}{$\begin{array}{c}\text { EFFECTIVE } \\
\text { SCHOOL }\end{array}$} & & \multicolumn{2}{c}{$\begin{array}{c}\text { INEFFECTIVE } \\
\text { SCHOOL }\end{array}$} \\
\cline { 2 - 3 } \cline { 5 - 6 } VARIABLE & $M$ & $\mathrm{SD}$ & & $M$ & $\mathrm{SD}$ \\
\hline Time on task & 1.00 & .00 & & 2.91 & .29 \\
Presentation of new material & 1.07 & .26 & & 2.11 & 1.05 \\
Independent practice & 1.13 & .35 & & 2.42 & .69 \\
High expectations & 1.33 & .49 & & 1.56 & .73 \\
Positive reinforcement & 1.00 & .00 & & 2.00 & .82 \\
Interruptions minimal & 2.00 & .00 & & 2.40 & .75 \\
Discipline & 1.13 & .35 & & 2.41 & .73 \\
Friendly ambience & 1.13 & .35 & & 2.41 & .80 \\
Student work displayed & 1.69 & .75 & & 2.43 & .98 \\
Appearance of room & 1.33 & .49 & & 1.57 & .66 \\
\hline
\end{tabular}

NOTE. $-1=$ evidence of effective behavior; $2=$ contradictory or weak evidence; $3=$ absence of effective behavior.

that very little variability is evident across teachers within each school, indicating a symbiotic relationship among good teachers and good schools.

In-depth analysis of field notes from classroom observations and interviews in these two schools suggested possible factors contributing to the differences. The schools in this pair were particularly wellmatched. Both had well-integrated student populations-about 50 percent white and 50 percent black. The schools were located a few blocks apart in a middle- to lower-middle-class suburban neighborhood. Both buildings were approximately 20 years old.

The principal at school 1 (the effective school) was described by one observer as "having her finger on the pulse of the school." She was frequently seen in the hallways and the classrooms; she was observed in her not-infrequent role of teaching a class. She appeared knowledgeable regarding every significant innovation in every classroom and saw to it that teachers were exposed to new and creative ideas.

This principal stated that the school had no weak teachers, just "some that are stronger in certain areas than in others." The principal's confidence was supported by one observer who, when asked about the weaker teachers, recalled, "I didn't see any."

Academic time was maximized in school 1. One observer noted how smoothly the day progressed, with children responding quickly to bells 


\section{Effective versus Ineffective Schools}

and directions. "As the kids are coming in from recess, the teacher is telling them what book to get out and what page to turn to." Observers agreed that the most salient feature of school 1 was effective use of time.

Hall bulletin boards were kept current and displayed academic themes as well as children's artwork. The research team was immediately impressed by the high level of excellence conveyed schoolwide. In the observers' experience, this tone was set and fostered by the school principal.

The principal at school 2 (the ineffective school) had had a teaching career marked with honors. This principal, too, stated that she had excellent, dedicated teachers. Although never observed in a classroom, she was visible in the hallways. She welcomed the visitors, conveying a "nothing-to-hide" attitude and expressing a sincere interest in the results of the study. She praised her school and staff, saying that everything there was "just great." "Everything was just great," noted one observer, "until we went into the classrooms." "The classrooms," continued another, "were total ... disasters."

If the amount of time spent on academics was the most impressive feature of school 1, the lack thereof was the unifying characteristic of school 2. A week-long fund-raising event was used as an excuse for the lack of class time spent on actual instruction. There was no attempt to tie the patriotic theme of the fund-raiser into instructional activities. Collecting money in one class period took 35 minutes. The investigators were dismayed at the number of interruptions attributed to such nonacademic projects. One member of the research team returned to the school two weeks later. He was unsurprised to find the "one-week" fund-raiser in its third week.

Classes typically began 15 minutes later than scheduled. Children returned from recess at their leisure. A 15-minute scheduled recess often lasted 30 minutes. A great deal of time was spent preparing for recess and lunch and return to class. Unfortunately, the relatively small amount of time spent in classrooms was often wasted.

There appeared to be little planning for instruction. One teacher related countless anecdotes about her childhood, usually irrelevant to the day's lesson. During one classroom observation, a parent arrived to discuss her son's classwork with this same teacher. Perhaps to facilitate the observation of her performance, the teacher discussed the boy's problems aloud in front of the researcher and the entire class. The mother retreated, embarrassed and frustrated.

Teachers spent a great deal of time in the faculty lounge. "They were escaping from the students," wrote one investigator. Students 
"were totally out of control.... The only time students were orderly was during lunch."

The appearance of teachers and the school itself were described as "very casual." Unlike the teachers at school 1, many of the female teachers here dressed in stretch slacks or jeans. The hall bulletin boards presented nonacademic themes.

This contrast in the bulletin boards of the two schools of this matched pair captured the primary difference between the two. The effective school was the school in which the principal, every member of the faculty, and the school building itself conveyed the message that students were in the school to learn and that no person, event, or excuse would be allowed to block that opportunity.

\section{Discussion}

The analysis of field notes from observation of 116 teachers in eight matched pairs of schools provided clear evidence that teachers in more effective schools consistently display more of the effective teaching behaviors identified by Rosenshine and others than do teachers in less effective schools. These findings are consistent whether analyzed at the school level or at the classroom level. Furthermore, there are significant differences on nearly all identified dimensions of effective teaching.

Since teachers at more effective schools behave differently from those at less effective schools, the next logical question became, What produces these differences in behavior? Stringfield et al. (1985) concluded that differences in one pair of schools revolved around four issues: (1) the principal at the effective school insisted on a clear, present academic focus; (2) the teachers at the effective school were interested in how well their students mastered basic skills rather than the likelihood that they would go to college; (3) there was a prominent display of symbols of academic excellence at the effective school; and (4) there was an emphasis on increasing the rate of interactive teaching in the classrooms of the effective school.

Observations about the pair of schools singled out for further discussion in this article echoed these conclusions. There were more public displays of academic excellence at the effective school as opposed to the ineffective one. There was also considerably more interactive teaching at the effective school.

Wimpelberg (1986) concluded that the "work center of the more effective school is the classroom." This centrality of the classroom was 


\section{Effective versus Ineffective Schools}

very evident in the effective school in this study, as opposed to the ineffective one. The classes at the effective schools began on time, were characterized by proper instructional techniques, and had few interruptions. The classes at the ineffective schools began late, did not consistently include defensible instructional techniques, and were constantly being interrupted.

The principal was the central figure who guarded the integrity of the classroom. The effective school principal in this study was visible in the classrooms, actually taught in some classrooms, and was aware of innovations in the classrooms of her school. The ineffective principal was never observed to enter into a classroom, was unaware of discipline problems throughout the school, and made no apparent attempt to decrease the constant interruptions. The ineffective principal seemed more concerned with schoolwide extracurricular and public relations activities than with academic instruction.

Wimpelberg (1986) summarized these differences in terms of bureaucratic and cultural images in the management of more and less effective schools. On the basis of the work of Firestone and Wilson (1985), Wimpelberg described the bureaucratic image as relying on bureaucratic procedures, having externally defined purposes, and being sensitive to adult (political) forces. The cultural image uses processes and symbols, has a broad and internally forged definition of purpose, and utilizes a "child-as-client" orientation.

In this study, the ineffective principal did not appear in the classroom except for the bureaucratic purpose of making evaluations. There was no visible internal definition of purpose at this school. The extended fund-raising event was an example of orientation to adult public relations activities rather than to the child as client.

In the effective school, there were many symbols of academic excellence-bulletin boards focusing on academic excellence, programs designed to recognize academic achievement, and so on. The "internally forged definition of purpose" was apparent in the uniformly excellent performance by the faculty on indicators of effective teaching. The child-as-client orientation was exemplified by the public acknowledgment of academic excellence, efficient use of time, and student scores above expectation on standardized achievement tests.

The need to incorporate knowledge of effective teaching into studies of effective schools has been noted. Verifying that effective schools are consistently coupled with more effective teachers inextricably merges school-effectiveness and teacher-effectiveness research. This finding, while answering concerns posed by Good and Brophy, is shadowed by a difficult question: Which came first? Is a school more effective 
because it attracts and employs effective teachers, or is teacher effectiveness fostered by characteristics of the school environment?

Although there can be no presumption of quantitatively answering the question on the basis of this research, qualitative data from at least one of the school pairs do suggest two areas for further investigation.

First, the administrative styles of the two principals were fundamentally different. The influence of the principal on individual teacher behavior deserves careful scrutiny.

Second, emphasis on academics appeared to permeate every aspect of the environment in the more effective school. Can effectiveness be attributed to this emphasis, and, if so, how and by whom is it conveyed to students and within the faculty and administrative structures?

Finally, longitudinal studies of the performance of teachers who begin in or are transferred to historically successful (and unsuccessful) schools are recommended. An understanding of the effect of schools on teacher development would be facilitated by such naturalistic research. This relationship between school and teacher effectiveness can best be described as symbiotic, yet further understanding is crucial to the design and implementation of any model for school improvement.

\section{References}

Anderson, L. W. "Teachers, Teaching, and Educational Effectiveness.” Paper presented at the East Coast Seminar for Title I Dissemination and Program Development, Philadelphia, April 1982.

Brookover, W., C. Beady, P. Flood, J. Schweitzer, and J. Wisenbaker. Schools Social Systems and Student Achievement: Schools Can Make a Difference. New York: Praeger, 1979.

$\rightarrow$ Cook, R. D. "Influential Observations in Linear Regressions." Journal of the American Statistics Association 74 (1979): 169-74.

$\rightarrow$ Donmeyer, R. "Cognitive Anthropology and Research on Effective Principals." Educational Administration Quarterly 21 (1985): 31-54.

Emmer, E., and C. Evertson. "Synthesis of Research on Classroom Management." Elementary School Journal 38 (1981): 342-47.

$\rightarrow$ Firestone, W., and B. Wilson. "Using Bureaucratic and Cultural Linkages to Improve Instruction: The Principal's Contribution." Educational Administration Quarterly 21 (1985): 7-30.

Good, T., and J. Brophy. "School Effects." In Third Handbook of Research on Teaching, edited by M. Whitrock. New York: Macmillan, 1986.

$\rightarrow$ Hanson, M., D. W. Gardner, and J. F. McNamara. "Ecological Inference in Administrative Reporting and Decision-Making." Educational Administration Quarterly 22 (1986): 63-89.

Hathaway, W. E. "Effective Teachers in Effective Schools." Paper presented at the meeting of the American Educational Research Association, Montreal, April 1983. 


\section{Effective versus Ineffective Schools}

Levin, T., and R. Long. Effective Instruction. Alexandria, Va.: Association for Supervision and Curriculum Development, 1981.

Purkey, S., and M. Smith. "Effective Schools: A Review." Elementary School Journal 83 (1983): 427-52.

$\rightarrow$ Rosenshine, B. "Teaching Functions in Instructional Programs." Elementary School Journal 83 (1983): 335-51.

Rousseeuw, P. J., and A. M. Leroy. Robust Regression and Outlier Detection. New York: Wiley, 1987.

Shoemaker, J., and H. Fraser. "What Principals Can Do: Some Implications for Studies of Effective Schooling." Phi Delta Kappan 63 (1981): 178-82.

$\rightarrow$ Sirotnik, K. A., and L. Burstein. "Measurement and Statistical Issues in Multilevel Research on Schooling." Educational Administration Quarterly 21 (1985): 169-85.

$\rightarrow$ Stallings, J. "Allocated Learning Time Revisited, or Beyond Time on Task." Educational Researcher 9 (1980): 11-15.

Stallings, J., and D. Kaskowitz. Follow through Classroom Observation Evaluation. Menlo Park, Calif.: SRI International, 1974.

Stringfield, S., C. Teddlie, and S. Suarez. "Classroom Interaction in Effective and Ineffective Schools: Preliminary Results from Phase III of the Louisiana School Effectiveness Study." Journal of Classroom Interaction 20 (1985): 31 37.

Teddlie, C., C. Falkowski, S. Stringfield, S. Desselle, and R. Garvue. The Louisiana School Effectiveness Study: Phase Two, 1982-84. Baton Rouge: Louisiana State Department of Education, 1984.

Weber, G. Inner City Children Can Be Taught to Read: Four Successful Schools. Washington, D.C.: Council for Basic Education, 1971.

Wimpelberg, R. K. "Bureaucratic and Cultural Images in the Management of More and Less Effective Schools." Paper presented at the meeting of the American Educational Research Association, San Francisco, April 1986. 